\title{
UV Resistance of Polystyrene co-Butyl Acrylate (PSBA) Encapsulated Lignin-saponite Nanohybrid Composite Film
}

\author{
Suguna Jairam ${ }^{\dagger}$, Ray Bucklin ${ }^{\dagger}$, Melanie Correll ${ }^{\dagger}$, Tamil Selvan Sakthivel ${ }^{\dagger \dagger}$, Sudipta Seal ${ }^{\dagger \dagger}$, John \\ Truett ${ }^{\dagger}$, and Zhaohui Tong ${ }^{{ }^{* *}}$ \\ 'Department of Agricultural \& Biological Engineering, University of Florida, PO Box 110570,
}

Gainesville, FL 32611, USA

${ }^{\sharp}$ Advanced Materials Processing and Analysis Center, Nanoscience and Technology Center, Materials Science and Engineering, University of Central Florida, Orlando, FL 32816, USA

\begin{abstract}
Protecting biological systems and organic materials from high ultraviolet (UV) radiation is a significant issue for engineering materials in both terrestrial and space applications. In this study, the synthesized composites of polystyrene butylacrylate (PSBA) encapsulated lignin based nanohybrid were evaluated as UV resistant cladding materials for both applications. The UV transmittance of the composite films and their physical, thermal, and chemical degradation after prolonged exposure to high UV radiation (10 Earth days and 30 Mars equivalent days) at low temperatures of $3.4{ }^{\circ} \mathrm{C}$ were examined. The results showed that the composite films blocked the UV radiation and there was no significant effect of UV radiation on film integrity, mechanical and thermal properties of the composite films when they were exposed to high intensity UV
\end{abstract}

\footnotetext{
${ }^{*}$ to whom correspondence should be addressed:

Zhaohui Tong, phone: (352) 392-864 ext. 103; Fax: (352)392-4092; Email: ztong@ufl.edu
} 
radiation $\left(132 \mathrm{~W} / \mathrm{m}^{2}\right)$ within $24 \mathrm{~h}$. Further, FTIR spectra of the composite films before and after UV radiation demonstrated that the films did not have notable oxidation degradation, although the glass transition temperature was slightly decreased with increased exposure time.

Keywords: UV Resistance, Lignin nanohybrid, Polystyrene-butylacrylate, Physical properties, Degradation 


\section{Introduction}

Both biological and physical structures can be damaged when they are exposed to high levels of ultraviolet radiation (UV) $)^{1-3}$. For example, in biological systems, high levels of UV radiation exposure causes DNA damage at the 5' end of the DNA chains which results in mutations in the genetics of the cell or can create site specific base pair mutations which lead to irregular translation and cell death ${ }^{4}$. Prolonged UV radiation also reduces the structural integrity of polymeric materials which can result in the degradation of physical structures ${ }^{1-3}$. Specifically, polymers that are exposed to high UV can have polymer chain breakage or oxidation of polymer units resulting in the reduction of thermal and mechanical properties of the materials. Reducing the damage caused by UV to both biological and physical structures is extremely important for future human space travel since space travelers and their transport vessels and other habitats such as Mars greenhouses will need to withstand high levels of UV radiation. Therefore, one important NASA goal is to develop UV-blocking composite polymers that enable the blocking of short wavelength UV while transmitting visible light for Bio-regenerative systems and greenhouse cladding materials.

The UV radiation on Mars is estimated as around $55 \mathrm{~W} / \mathrm{m}^{2}$ per day at the equator (at Vernal Equinox, Zenith angle $0^{\circ}$ ), which is similar to Earths' at the same relative time/location (55 $\left.\mathrm{W} / \mathrm{m}^{2}\right)^{5}$. But the UVB and UVC radiation at $315-100 \mathrm{~nm}$ is estimated at almost 7 times that of Earths' UV B and C radiation, at $13 \mathrm{~W} / \mathrm{m}^{2}$ and $2 \mathrm{~W} / \mathrm{m}^{2}$ respectively, which are the wavelengths largely attributed to tissue degradation ${ }^{5,6}$. Therefore, the development of composite polymers that maintain their structural integrity under high UV radiation on the Martian surface is critical. Several research groups have worked on polymeric materials that protect against UV radiation and heat using inorganic fillers including metallic oxides (zinc, iron and silica) $)^{7-10}$, carbon 
nanotubes $^{11-13}$, and plant based fibers ${ }^{2,14,15}$. Glass and cement were reported to improve structural stability of polymeric materials under high sunlight exposure. Most of these materials alleviate material loss or structural damage by either reducing the rate of degradation or modifying the process of degradation. For instance, metallic and nano fillers cause the dispersion of high frequency radiation because the small particle size results in reduced exposure of the bulk material and the rate of degradation ${ }^{16}$. Materials like resins and glassy polymers reinforced by carbon nanotubes and natural fibers undergo chemical oxidation before bulk polymer degradation, which causes the cracks and fractures ${ }^{16}$ although they can still maintain their functionality and long shelf life in extreme UV radiation environments. However, the polymers demonstrating good UV blocking have low ductility and are highly brittle, which reduces their use in applications requiring bendable, expandable cladding materials. The bendable polymers such as epoxides and acrylic resins were mixed with zinc and its oxide to prepare flexible composite materials with UV resisitance ${ }^{17}$. However, incorporating the metallic oxides into the polymer matrix led to the oxidation of the carbon chains and the chemical breakdown of the polymer chains ${ }^{17}$.

Lignin, which composes $18-25 \%$ of plant biomass, is a highly cross-linked aromatic polymer of phenylpropane units ${ }^{18,19}$. It has been widely reported to block UV radiation as the natural defense mechanism in plant systems ${ }^{20,21,22}$. The blocking of phenolic $\mathrm{OH}$ groups in lignin prevents the formation of phenoxy radicals that causes photodegradation in the plant material ${ }^{23}$. It has been reported that lignin-cellulose nanocomposite prepared from lignin (either synthetic or biologically extracted) and nanocrystal cellulose exhibited high-performance optical properties while blocking in the UV spectrum ${ }^{14,24}$. 
In our previous work, we prepared composite latex film through the encapsulation of ligninsaponite nanohybrid into polystyrene butyl acrylate (PSBA) copolymer matrix via miniemulsion polymerization and the resultant film had improved mechanical, thermal, and gas barrier properties in comparison with pure PSBA film ${ }^{25}$. Compared to the previous study, a new ligninbased nanophase (lignin-clay hybrid) instead of metallic oxides was uniformly dispersed into copolymer matrix. Although lignin has been reported to block UV radiation, how lignin as a nanophase at a very low loading level affects the UV-resistance and the degradation of the copolymer under high UV radiation is not clear. Herein, we studied the effects of different lignin nanohybrid loadings of the composite films on their UV blocking properties. We further studied the variance of mechanical and thermal properties of the composite films before and after UV exposure in a UV chamber which mimics the UV radiation in Mars. Fourier Transform Infrared spectroscopy (FTIR) was used to detect the chemical degradation of the composite films before and after UV radiation.

\section{Materials and Methods}

\subsection{Candidate polymeric materials}

Composite latex film of polystyrene co-butyl acrylate (PSBA) films encapsulating lignin nanohybrid was synthesized via miniemulsion polymerization based on our previous work $^{22}$. Briefly, lignin was extracted from the fermentation broth of a cellulosic ethanol biorefinery process (dilute phosphoric acid and steam explosion pretreatment followed by a liquefaction and simultaneous saccharification and fermentation process $(\mathrm{L}+\mathrm{SScF})$ ) using sugarcane bagasse as the feedstock). $\mathrm{NaOH}$ at elevated temperature then extracted the lignin. This lignin was modified and loaded with saponite together to form lignin-saponite hybrid as previously described. After 
that, PSBA encapsulated lignin-saponite nanohybrid was synthesized via miniemulsion polymerization at various loading rates, including $0.12,0.3$, and $0.6 \mathrm{~g}$ based on $12 \mathrm{~g}(1 \%, 2.5 \%$, and $5 \%$ by w.t.) of the co-monomer ${ }^{20}$. The uniform polymer films ( $1 \mathrm{~mm}$ thickness) with various loading levels of lignin nanohybrid were dried, cut into dog-bone shape with a width of $5 \mathrm{~mm}$, a length of $24 \mathrm{~mm}$ for the narrow portion (gauge length $8 \mathrm{~mm}$ ) and total length of $40 \mathrm{~mm}$ (according to ASTM standard D1708) and exposed to high intensity UV radiation.

\subsection{UV chamber and UV radiation test}

The composite samples were treated with high levels of UV light to determine the degradation of materials under high intensity UV exposure that can be found on the surface of planets and in outer space. The approach has been reported by the previous work ${ }^{26}$ where a Mars Simulation Chamber (MSC) at Kennedy Space Center was used to treat samples to a "Martian" environment and test for the transmittance of several plastic materials. We constructed a UV chamber with a UV lamp similar to the MSC as shown in Fig. 1. This UV system is more costeffective than the MSC, but requires more intensive monitoring for its temperature control. The pressure and temperature was not altered to Mars levels since these tests were primarily to study the UV resistance of these new organic materials.

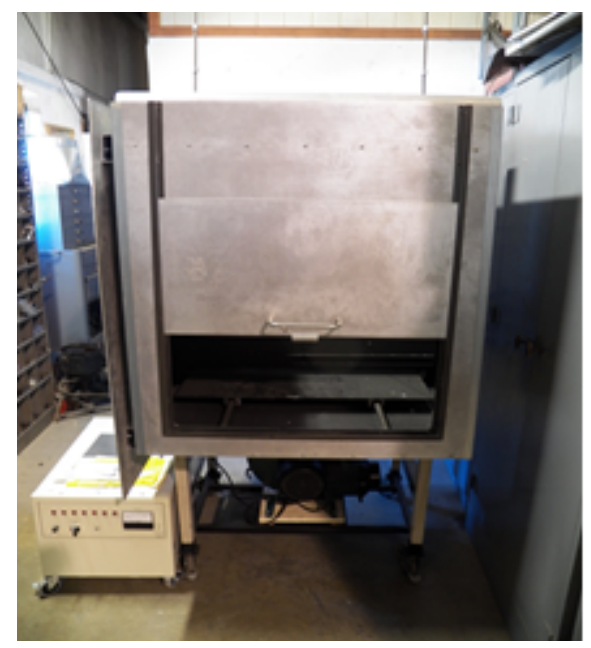


Figure 1: UV chamber constructed at ABE dept., UF

Dog-bone shaped samples of the polymer film were cut based on standard ASTM D 1708-10 and were placed on an aluminum plate and maintained at a temperature of $3.4{ }^{\circ} \mathrm{C} \pm 2{ }^{\circ} \mathrm{C}{ }^{27}$. Quartz glass covers were used to prevent the accumulation of moisture, but allow the maximum transmission rate of UV radiation. The polymer samples were then irradiated with high intensity UV using a $5000 \mathrm{~W}$ Hanovia UV lamp (6C100.241, Hanovia Specialty Lighting LLC, New Jersey, USA) at an intensity of $149.7 \mathrm{~W} / \mathrm{m}^{2}$ measured by a UV radiometer (Hanovia Specialty Lighting LLC, New Jersey, USA). Irradiation was broad range and maintained at levels equivalent to 10 Earth or 30 Mars equivalent days at constant distance of $2.5 \mathrm{ft}$ maintained at 3.4 $\pm 2{ }^{\circ} \mathrm{C}$ and at $18.5 \pm 2 \%$ relative humidity for $6,12,18$, and $24 \mathrm{~h}$. Original and exposed samples were then tested for changes in chemical structure, UV transmittance, and thermal and mechanical properties.

\subsection{Characterization}

Fourier Transform Infrared Spectroscopy (FTIR) was used to investigate changes in chemical bonding of the composite films to estimate chemical degradation of the composite films after exposure to UV radiation. Solid film samples were directly used for FTIR analysis with attenuated total reflection (ATR). FTIR spectra were recorded on a Spectrum One spectrometer (PerkinElmer, Massachusetts, USA). FTIR took 10 scans for each sample with the scanning range from 400 to $4000 \mathrm{~cm}^{-1}$. UV transmittance of the composite films at different loadings of lignin nanohybrids before and after 24-h UV exposure was measured on a PerkinElmer Lambda 7505 UV-Vis spectrophotometer (Massachusetts, USA). Thermogravimetric analysis was performed using a Mettler Toledo thermal analyzer (OH, USA) at a heating rate of $20{ }^{\circ} \mathrm{C} / \mathrm{min}$ and at a temperature up to $600{ }^{\circ} \mathrm{C}$. Differential scanning calorimetry (DSC) was carried out on a 
Seiko DSC 6200 (Seiko instruments, Inc, Japan) under nitrogen flow at $10{ }^{\circ} \mathrm{C} / \mathrm{min}$ heating rate. Samples were crimp sealed in $40-\mu \mathrm{L}$ aluminum crucibles. All samples were scanned from 25 to $190{ }^{\circ} \mathrm{C}$ at a heating rate of $10{ }^{\circ} \mathrm{C} / \mathrm{min}$ under nitrogen. The heating and cooling cycles were repeated 3 times under constant gaseous nitrogen flow for glass transition temperature measurement. Tensile strength of composite films was performed on an Instron test machine (Model 5566, load cell capacity of 40 N, Instron instruments, Grove City, PA) with a crosshead speed of $10 \mathrm{~mm} / \mathrm{min}$ based on ASTM standards ${ }^{27}$. The crosshead extension was used as specimen deformation. The composite films with dog-bone shape were used for this testing. Five replicates were tested for each composite. Young's moduli of all composites were determined from the linear portion of the stress-strain curves. Two way analysis of variance (ANOVA) was used to compare the mean differences in tensile strength and Young's moduli for various treatment levels (lignin loading and UV exposure time) at 95\% significance level. Multiple comparison and Tukey's honest significant difference (HSD) test was carried out for means with significant differences at a $95 \%$ confidence interval $(\alpha=0.05)$ using R 3.1.3 software package ${ }^{28}$.

\section{Results and Discussion}

3.1 Incident UV flux calculation, shape integrity, and UV transmittance of the composite films before and after UV exposure

The amount of UV energy exposure of the samples in the UV chamber was estimated and compared to that experienced on Earth. The UV exposure from the lamp was estimated at 149.7 $\mathrm{W} / \mathrm{m}^{2}$ as compared to $15 \mathrm{~W} / \mathrm{m}^{2}$ (measured in the mid-day of Gainesville, Florida, clear sunny day) on Earth. The use of the Quartz glass cover on the sample surface resulted in 11\% loss, 
therefore, the UV exposure of the composite samples in the UV chamber was approximately 132 $\mathrm{W} / \mathrm{m}^{2}$ during the tests. At this high intensity, the samples at $1,2.5$, and $5 \%$ loading levels of lignin-based nanohybrid (based on weight of the comonomer) were exposed to a UV lamp in the UV chamber at varying time intervals of $6,12,18$, and 24 h. Fig. 2 shows the film morphologies at varying lignin nanohybrid loadings after UV exposure from 6 to $24 \mathrm{~h}$. No apparent change in shape or surface morphologies was observed for all the samples up to $24 \mathrm{~h}$ exposure time. After $24 \mathrm{~h}$ exposure, bubbles started to form on the surface of the sample films, indicating the initiation of film degradation. Direct UV radiation has been reported to cause polymer chain cleavage at high intensities of prolonged exposure. In the absence of oxidation, local hot spots were likely created within the polymer matrix by local thermal transitions leading to bubbling, crack formation, and physical deformation ${ }^{16,29}$. These phenomena were marginally noticeable in $24 \mathrm{~h}$ exposed samples and were in tandem with previously reported polymer degradation studies. In comparison with the composite films, the neat (empty) PSBA films were deformed completely within $6 \mathrm{~h}$ of UV exposure, with disfiguration, bubble, pin-hole formation, and discoloration making these samples unsuitable for further testing.

According to current Martian environment estimates, the flux of UV on Mars is comparable with that on Earth, but the UVB and UVC radiation at $300-100 \mathrm{~nm}$ is estimated at almost 7 times that of Earths' UV B and C radiation ${ }^{5,6}$. Considering both the lower wavelength limit of spectrophotometer of $200 \mathrm{~nm}$ and the UV wavelength range in Martian environment, Fig. 3 shows the UV transmittance of the composite films from 200 to $400 \mathrm{~nm}$ before and after $24 \mathrm{~h}$ UV exposure. At the lower end of the UV wavelength range (from 200 to $300 \mathrm{~nm}$ ), less than $1.5 \%$ of UV transmittance was obtained indicating almost completely blockage of incident UV 
even after exposure of $24 \mathrm{~h}$. We observed that there was no notable change in UV transmittance even

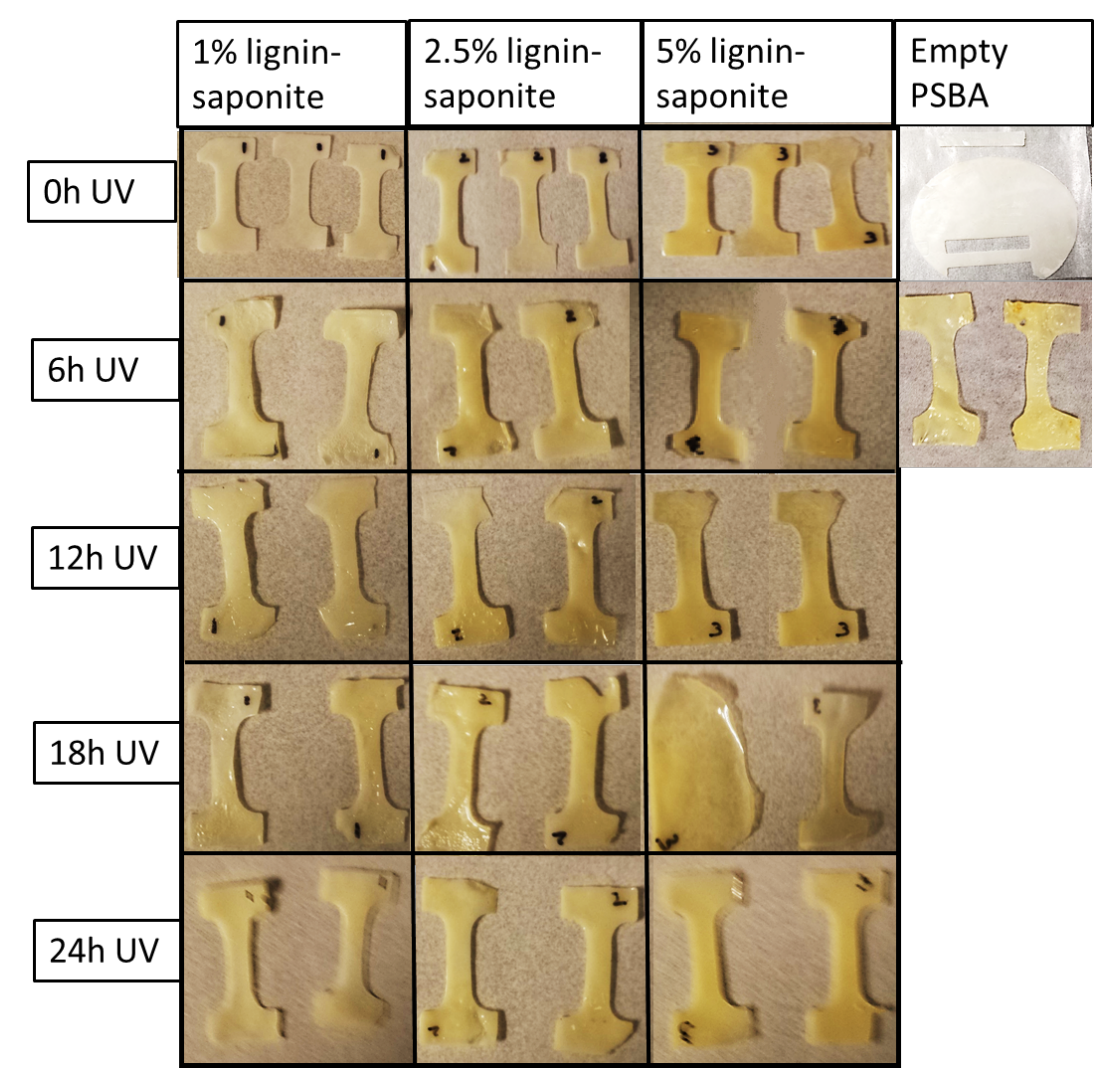

Figure 2: The shape integrity of PSBA encapsulated lignin nanohybrid composite films at various UV exposure times.

after prolonged exposure as well. It is known that oxidation and free radical formation usually occurs when a phenolic $\mathrm{OH}$ group is in resonance with its aromatic backbone, which results in the formation of quinoid structure ${ }^{23}$. The modification of lignin for incorporation within the polymer matrix successfully blocks phenolic $\mathrm{OH}$ groups ${ }^{25}$ and prevents the formation of phenolic radicals and the degradation of lignin phenolic structure. In addition, the exfoliation and uniform distribution of lignin nanohybrid in the polymer matrix allows the uniform distribution of lignin nanohybrid in the matrix, leading to high UV-blocking property at a very low loading (less than $5 \%$ ) of lignin nanohybrid. 
3.2 The effects of UV radiation on the mechanical properties of composite films

The mechanical properties of composite films with varying loading levels of ligninnanohybrids were examined using an Instron testing machine. Neat PSBA copolymer samples had prominent degradation (discoloration, disfiguring, and formation of bubbles and holes) after

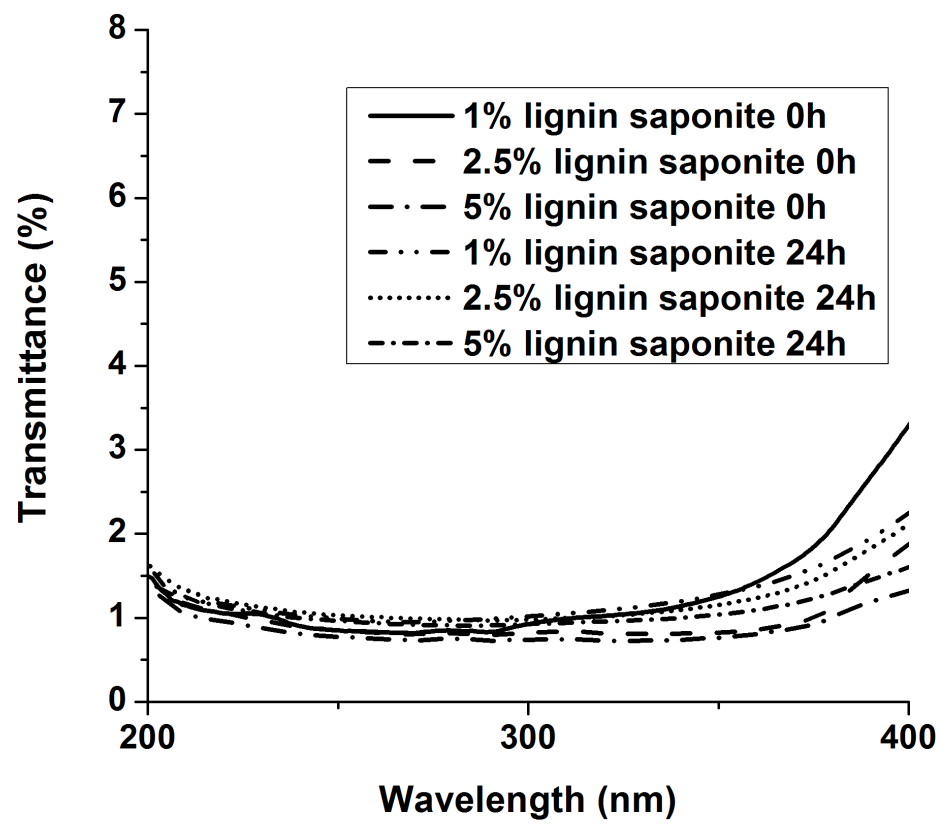

Figure 3: UV transmittance of PSBA encapsulated lignin nanohybrid composite films in the range of $200 \mathrm{~nm}$ to $400 \mathrm{~nm}$ at $0 \mathrm{~h}$ and $24 \mathrm{~h} \mathrm{UV}$ exposure.

$6 \mathrm{~h}$ of UV exposure and were not strong enough for tensile testing. The composite films with the addition of $1,2.5$, and $5 \%$ of lignin nanohybrids did not show any apparent degradation under UV exposure for $24 \mathrm{~h}$ and at a high UV intensity (10 times stronger than earth UV radiation measured in Gainesville, FL). This result indicates that lignin-clay nanohybrid plays a major role on the UV blocking properties of the composite films. As shown in the Fig. 4, the tensile strength and Young's moduli of the composite films in all three lignin nanohybrid loading levels after UV radiation within $24 \mathrm{~h}$ were greater than those of the original composite films without any UV 
exposure. This result (along with FTIR information) suggests that there are multiple $\mathrm{C}-\mathrm{H}$ cleavages along the polymer matrix, which causes a local reduction in chain lengths. The reduced chain lengths can better redistribute the applied load about the lignin-saponite entanglements ${ }^{30}$ thereby allowing the composite to withstand a greater strain ${ }^{31}$ and hence, leads to increase in modulus and tensile strength ${ }^{1,2}$.

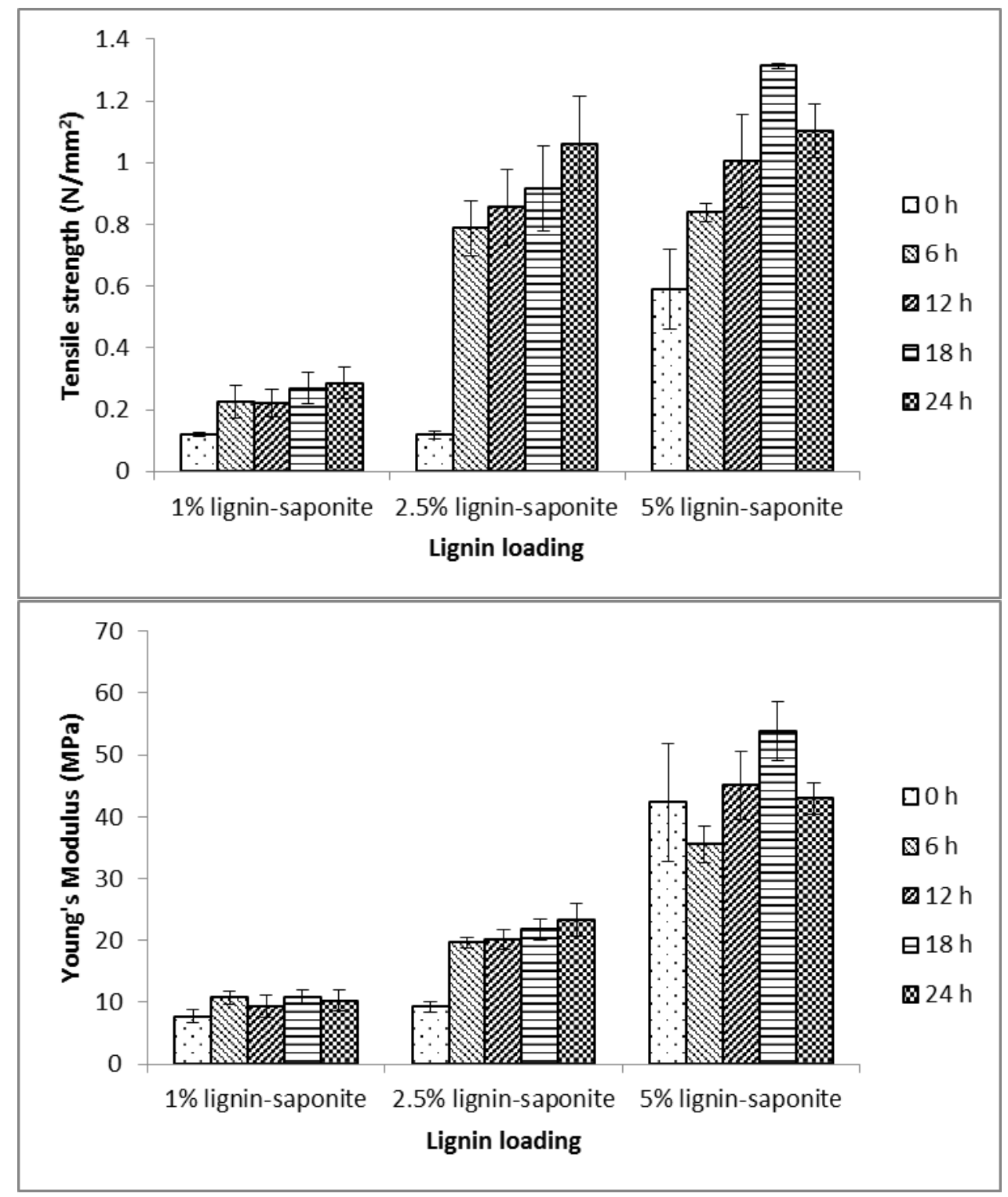

Figure 4 Tensile strength and Young's moduli of PSBA encapsulated lignin nanohybrids composite films at various UV exposure times. 
Two way ANOVA analysis was carried out to estimate the effects of lignin nanohybrid loading levels and UV exposure time on Young's moduli and tensile strengths. The results show that lignin loading levels and UV exposure time significantly affected the tensile strengths of the composite films, namely the maximum stress at break $(\mathrm{p}<0.001, \mathrm{t}$ test, $\alpha=0.05)$. The loading levels of lignin nanohybrids significantly affected Young's moduli of the composite films $(\mathrm{p}<0.001, \mathrm{t}$ test, $\alpha=0.05)$. This result agrees well with previous research ${ }^{37,38}$. However, the radiation time did not have significant influence on the Young's moduli of the composite films. The UV exposure time significantly affected the maximum stress at breakage, which may be attributed to the initiation of some micron cracking during the degradation process. But the entire stress-strain relationship (moduli) of the films was not significantly affected.

3.3 The effects of UV radiation on the thermal properties of the composite films

Differential scanning calorimetry (DSC) was used to measure the glass transition temperature (Tg) of the composite films with varying lignin nanohybrid at 0,12 , and $24 \mathrm{~h} \mathrm{UV}$ exposure as shown in Table 1. The Tg of the composite films was increased with the loading level of lignin nanohybrid because lignin-saponite hybrid had higher Tg than that of the PSBA copolymer $\left(23.19^{\circ} \mathrm{C}\right)$. The UV exposure time had slightly negative effects on the Tg of the composite films, which possibly indicated that the polymer matrix was degraded ${ }^{29,32}$. This is further corroborated by FTIR data, which shows that UV radiation results in the random scission of the polymer chain backbone ${ }^{1,2,33}$. The breaking of these chains leads to effects similar to that of low molecular weight polymer and results in a reduction in thermal stability and $\mathrm{Tg}$. 
Table 1: The glass transition temperature $(\mathrm{Tg})$ of the composite films with varying lignin nanohybrids and at different UV exposure times

\begin{tabular}{|c|c|c|c|}
\hline \multirow{2}{*}{ UV exposure time (h) } & \multicolumn{3}{|c|}{ Glass transition temperature $\left.\mathbf{( T g} \mathbf{~}^{\mathbf{O}} \mathbf{C}\right)$} \\
\cline { 2 - 4 } & $\begin{array}{c}\mathbf{1 \%} \text { ) lignin- } \\
\text { saponite }\end{array}$ & $\begin{array}{c}\mathbf{2 . 5 \%} \\
\text { saponite }\end{array}$ & $\begin{array}{c}\mathbf{5 \%} \text { lignin- } \\
\text { saponite }\end{array}$ \\
\hline $\mathbf{0}$ & 41.4 & 43.1 & 45.6 \\
\hline $\mathbf{1 2}$ & 36.7 & 36.9 & 39.1 \\
\hline $\mathbf{2 4}$ & 35.1 & 35.1 & 37.9 \\
\hline
\end{tabular}

TGA was used for detecting thermal degradation of the composites at different UV exposure. At $24 \mathrm{~h}$ exposure, the curve shifts to the left owing to UV based degradation at such prolonged radiation and high UV intensities. It is however noteworthy that polymer degradation temperature remains unchanged indicating that majority of degradation is limited in the nanophase.

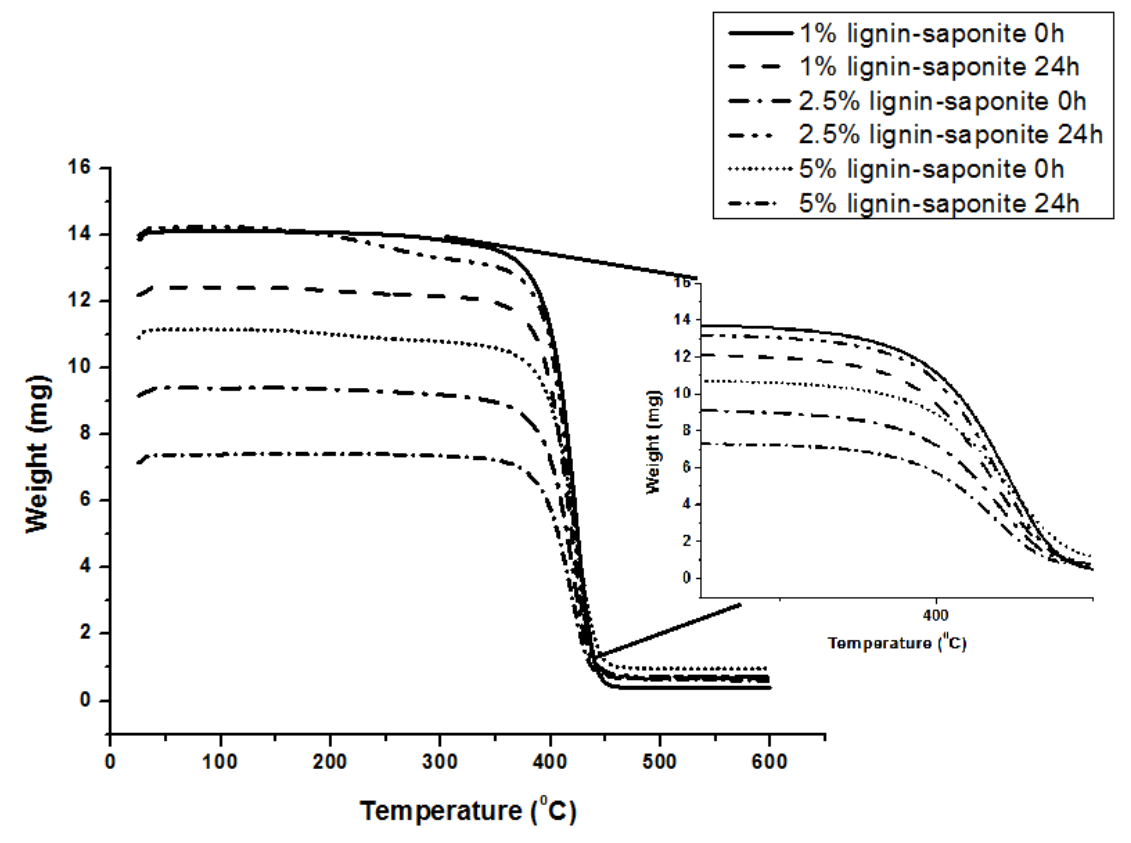

Figure 5: Thermogravimetric analysis of the composite films with $1 \%, 2.5 \%$, and 5\% of lignin nanohybrids before and after $24 \mathrm{~h}$ UV exposure. 
3.4 FTIR analysis of composite films before and after UV exposure

FTIR analysis was used to detect possible chemical degradation of the composite films before and after UV exposure for $24 \mathrm{~h}$. As seen in the fig. 6, FTIR spectra of composite films before and after $24 \mathrm{~h} \mathrm{UV}$ exposure are nearly identical except the intensity of the C-H bond. The characteristic C-C stretching was observed at $1000 \mathrm{~cm}^{-1}$ and C-H between 2800 and $2900 \mathrm{~cm}^{-1}$ from the polymer backbone. The $\mathrm{C}-\mathrm{H}$ transmittance intensities are noticeable lower for the samples treated with UV radiation and can be attributed to the cleavage of polymer chains by the UV radiation ${ }^{1}$. Similar results have been reported for other acrylate systems that have been either degraded by photo irradiation or excess curing with UV radiation ${ }^{17,34}$. The peaks at 1490 and $1450 \mathrm{~cm}^{-1}$ were attributed to phenolic $\mathrm{OH}$ vibration from lignin. This phenolic $\mathrm{OH}$ group is intact

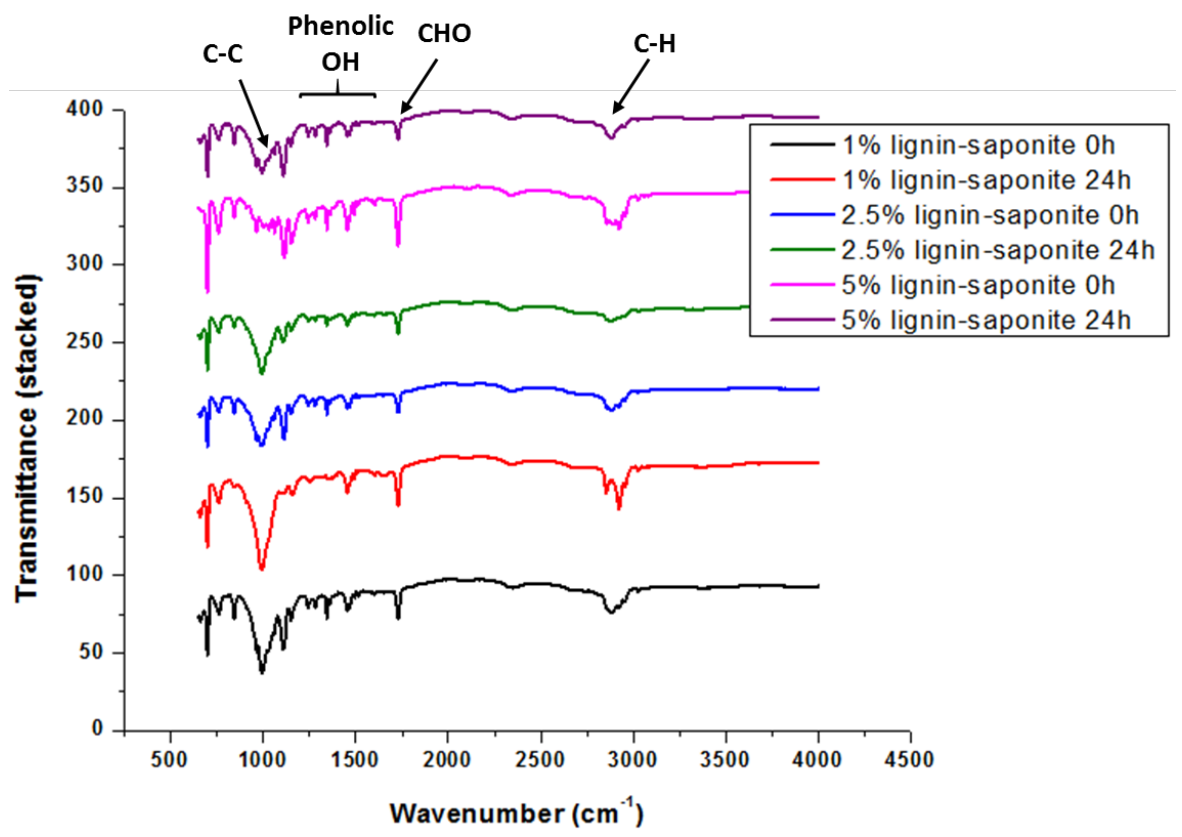

Figure 6: FTIR analysis of latex films of PSBA encapsulated 1, 2.5, and 5\% lignin nanohybrids at $0 \mathrm{~h}$ and $24 \mathrm{~h} \mathrm{UV}$ exposure 
after UV radiation and is reported to be instrumental in UV blocking properties of lignin ${ }^{23,35}$. The peak at $1670 \mathrm{~cm}^{-1}$ was attributed to characteristic $\mathrm{CHO}$ vibration from lignin. However, the peak for the oxidized functional group $\mathrm{COOH}$ of lignin was not observed from all the composite films after UV exposure, which indicated that there was no obvious oxidation degradation for the composite films after UV exposure. The absence of oxidation products from UV radiation explains the relative stability of the films and conservation of mechanical strength indicating that the presence of lignin nanohybrid within the composite prevents ionic degradation of polymeric units $^{17,36}$.

\section{Conclusions}

This work aims to evaluate the UV blocking properties of PSBA latex films from the addition of varied mass ratios of lignin nanohybrids. The results indicated that nanocomposite films within all the varied nanohybrid loading levels could effectively block approximately $98 \%$ of UV transmittance at high UV intensity $\left(132 \mathrm{~W} / \mathrm{m}^{2}, 10\right.$ times stronger than the UV radiation on earth) for $24 \mathrm{~h}$ UV radiation. The tensile strength and Young moduli of the composite films under $24 \mathrm{~h} \mathrm{UV}$ radiation were greater than that without radiation for all the nanocomposite samples. The nanocomposite films at maximum loading of lignin-clay nanohybrid (5\%) achieved the maximum tensile strength and Young moduli. The glass transition temperature (Tg) was slightly decreased with the increase of UV exposure time and the degradation temperature was decreased after $24 \mathrm{~h}$ UV radiation as well. The FTIR result does not show any evidence of oxidation degradation of the composite films. The benefits of this research include the use of small amount of lignin nanohybrid (less than 5\%) as a safe, effective, and sustainable alternative instead of metal oxides, nano carbon, and other natural fibers to make flexible films with high 
UV resistibility. The inherent structural and anti-UV properties of lignin enable higher life span of the composite films under extreme radiation conditions for both terrestrial and space applications.

\section{Acknowledgement}

The authors want to acknowledge of the funding by Space Florida and the National Aeronautics and Space Administration through the University of Central Florida's NASA Florida Space Grant Consortium, Space Research Initiative program and the U.S. Department of Energy's International Affairs under award number DE-PI0000031 from the U.S. Department of Energy's Office of Energy Efficiency and Renewable Energy, Bioenergy Technologies Office. 


\section{References}

1. Çaykara T, Güven O UV degradation of poly(methyl methacrylate) and its vinyltriethoxysilane containing copolymers Polym Degrad Stab 1999;65(2):225-229.

2. Azwa ZN, Yousif BF, Manalo AC, Karunasena W A review on the degradability of polymeric composites based on natural fibres Mater Des 2013;47:424-442.

3. Qin H, Zhao C, Zhang S, Chen G, Yang M Photo-oxidative degradation of polyethylene/montmorillonite nanocomposite Polym Degrad Stab 2003;81(3):497-500.

4. Harm W Biological effects of ultraviolet radiation. Cambridge University Press. 1980.

5. Cockell C, Catling D, Davis W, et al. The ultraviolet environment of Mars: Biological implications past, present, and future Icarus 2000;146(2):343-359.

6. Patel M, Zarnecki J, Catling D Ultraviolet radiation on the surface of Mars and the Beagle 2 UV sensor Planet Space Sci 2002;50(9):915-927.

7. Wong T, Tam W, Etches JA, Wang W, Leng J, Lau K Feasibility of using ZnO/epoxy filled hollowed glass fibres (HGFs) for UV resistant polymer composites Mater Lett 2014;128:220-223.

8. Wong T, Lau K, Tam W, Leng J, Etches JA UV resistibility of a nano-ZnO/glass fibre reinforced epoxy composite Mater Des 2014;56:254-257.

9. Gao Y, Gereige I, El Labban A, Cha D, Isimjan TT, Beaujuge PM Highly Transparent and UV-Resistant Superhydrophobic SiO2-Coated ZnO Nanorod Arrays Acs Applied Materials \& Interfaces 2014;6(4):2219-2223.

10. Ebert D, Bhushan B Transparent, Superhydrophobic, and Wear-Resistant Coatings on Glass and Polymer Substrates Using SiO2, ZnO, and ITO Nanoparticles Langmuir 2012;28(31):1139111399. 
11. Liu Y, Wang X, Qi K, Xin J Functionalization of cotton with carbon nanotubes Journal of Materials Chemistry 2008; 18(29):3454-3460.

12. Mondal S, Hu J A novel approach to excellent UV protecting cotton fabric with functionalized MWNT containing water vapor permeable PU coating J Appl Polym Sci 2007;103(5):3370-3376.

13. Najafi E, Shin K Radiation resistant polymer-carbon nanotube nanocomposite thin films Colloids Surf Physicochem Eng Aspects 2005;257:333-337.

14. Faruk O, Bledzki AK, Fink H, Sain M Biocomposites reinforced with natural fibers: 20002010 Progress in Polymer Science 2012;37(11):1552-1596.

15. Majeed K, Jawaid M, Hassan A, et al. Potential materials for food packaging from nanoclay/natural fibres filled hybrid composites Mater Des 2013;46:391-410.

16. Awaja F, Nguyen M, Zhang S, Arhatari B The investigation of inner structural damage of $\mathrm{UV}$ and heat degraded polymer composites using X-ray micro CT Composites Part A-Applied Science and Manufacturing 2011;42(4):408-418.

17. Yang R, Christensen PA, Egerton TA, White JR Degradation products formed during UV exposure of polyethylene-ZnO nano-composites Polym Degrad Stab 2010;95(9):1533-1541.

18. Vanholme R, Demedts B, Morreel K, Ralph J, Boerjan W Lignin Biosynthesis and Structure Plant Physiol 2010;153(3):895-905.

19. Glasser WG, Sarkanen SLignin: properties and materials. American Chemical Society. 1989 (397).

20. Alexieva V, Sergiev I, Mapelli S, Karanov E The effect of drought and ultraviolet radiation on growth and stress markers in pea and wheat Plant, Cell Environ 2001;24(12):1337-1344.

21. Smith RC, Prezelin BB, Baker KS, et al. Ozone depletion: ultraviolet radiation and phytoplankton biology in antarctic waters Science 1992;255(5047):952-959.

22. Gosselink RJA, Snijder MHB, Kranenbarg A, Keijsers ERP, de Jong E, Stigsson LL Characterisation and application of NovaFiber lignin Industrial Crops and Products 2004;20(2):191-203.

23. George B, Suttie E, Merlin A, Deglise X Photodegradation and photostabilisation of woodthe state of the art Polym Degrad Stab 2005;88(2):268-274.

24. Hambardzumyan A, Foulon L, Chabbert B, Aguie-Beghin V Natural Organic UV-Absorbent Coatings Based on Cellulose and Lignin: Designed Effects on Spectroscopic Properties Biomacromolecules 2012;13(12):4081-4088. 
25. Jairam S, Tong Z, Wang L, Welt B Encapsulation of Bio-based Lignin-saponite nanohybrid into Polystyrene co-Butyl Acrylate (PSBA) Latex via Miniemulsion

Polymerization2013;1(12):1637.

26. Smith SJ, Townley JA, Martin-Ryals AD, Truett J, Palaia JE, Schuerger AC, Bucklin RA and Correll MC. Testing of Greenhouse Cladding Materials for Space Environments Appl Eng Agric 2011;27(3):449-456.

27. ASTM D 1708-10ASTM D 1708-10 Standard Test Method for Tensile Properties of Plastics by Use of Microtensile Specimens. ASTM International, West Conshohocken, PA. .

28. R Development Core TeamR: A language and environemnt for statistical computing 2008;3.1.

29. Kamrannejad MM, Hasanzadeh A, Nosoudi N, Mai L, Babaluo AA Photocatalytic degradation of polypropylene/TiO2 nano-composites Materials Research 2014(AHEAD):0-0.

30. Fu S, Lauke B Effects of fiber length and fiber orientation distributions on the tensile strength of short-fiber-reinforced polymers Composites Sci Technol 1996;56(10):1179-1190.

31. Termonia Y, Meakin P, Smith P Theoretical study of the influence of the molecular weight on the maximum tensile strength of polymer fibers Macromolecules 1985;18(11):2246-2252.

32. Sanji T, Nakatsuka Y, Ohnishi S, Sakurai H Preparation of nanometer-sized hollow particles by photochemical degradation of polysilane shell cross-linked micelles and reversible encapsulation of guest molecules Macromolecules 2000;33(23):8524-8526.

33. Çaykara T, Güven O UV degradation of poly(methyl methacrylate) and its vinyltriethoxysilane containing copolymers Polym Degrad Stab 1999;65(2):225-229.

34. Chattopadhyay D, Panda SS, Raju K Thermal and mechanical properties of epoxy acrylate/methacrylates UV cured coatings Progress in Organic Coatings 2005;54(1):10-19.

35. Kosikova B, Labaj J Lignin-Stimulated Protection of Polypropylene Films and Dna in Cells of Mice Against Oxidation Damage BioResources 2009;4(2):805-815.

36. Nowicki M, Richter A, Wolf B, Kaczmarek H Nanoscale mechanical properties of polymers irradiated by UV Polymer 2003;44(21):6599-6606.

37. Dutta A, Srinivasan A T Synthetic staggered architecture composites Materials \& Design 2013; 46: 802-808.

38. Dutta, A, Andy V, Srinivasan A T High strain rate mechanical behavior of seashell-mimetic composites: Analytical model formulation and validation Mechanics of Materials 2013;55: 102111. 


\section{Figure Captions}

Figure 1: UV chamber constructed at ABE Dept., UF ..................................................... 7

Figure 2: The shape integrity of PSBA encapsulated lignin nanohybrid composite films at

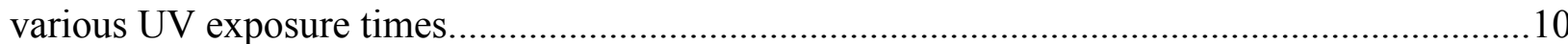

Figure 3: UV transmittance of PSBA encapsulated lignin nanohybrid composite films in the

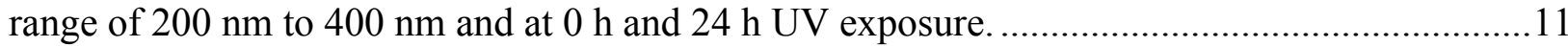

Figure 4 Tensile strength and Young's moduli of PSBA encapsulated lignin nanohybrids

composite films at various UV exposure times.......................................................... 12

Figure 5: Thermogravimetric analysis of the composite films with $1 \%, 2.5 \%$, and $5 \%$ of lignin

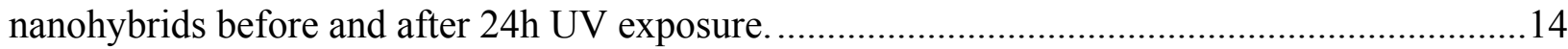

Figure 6: FTIR analysis of latex films of PSBA encapsulated 1\%, 2.5\%, and 5\% lignin

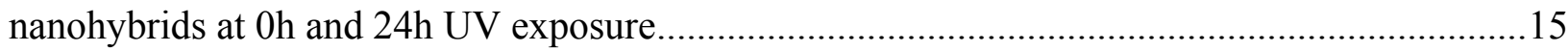




\section{Tables}

Table 1: The glass transition temperature $(\mathrm{Tg})$ of the composite films with varying lignin

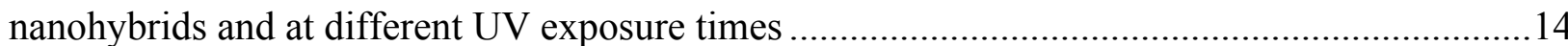


PSBA encapsulated lignin nanohybrid composite films

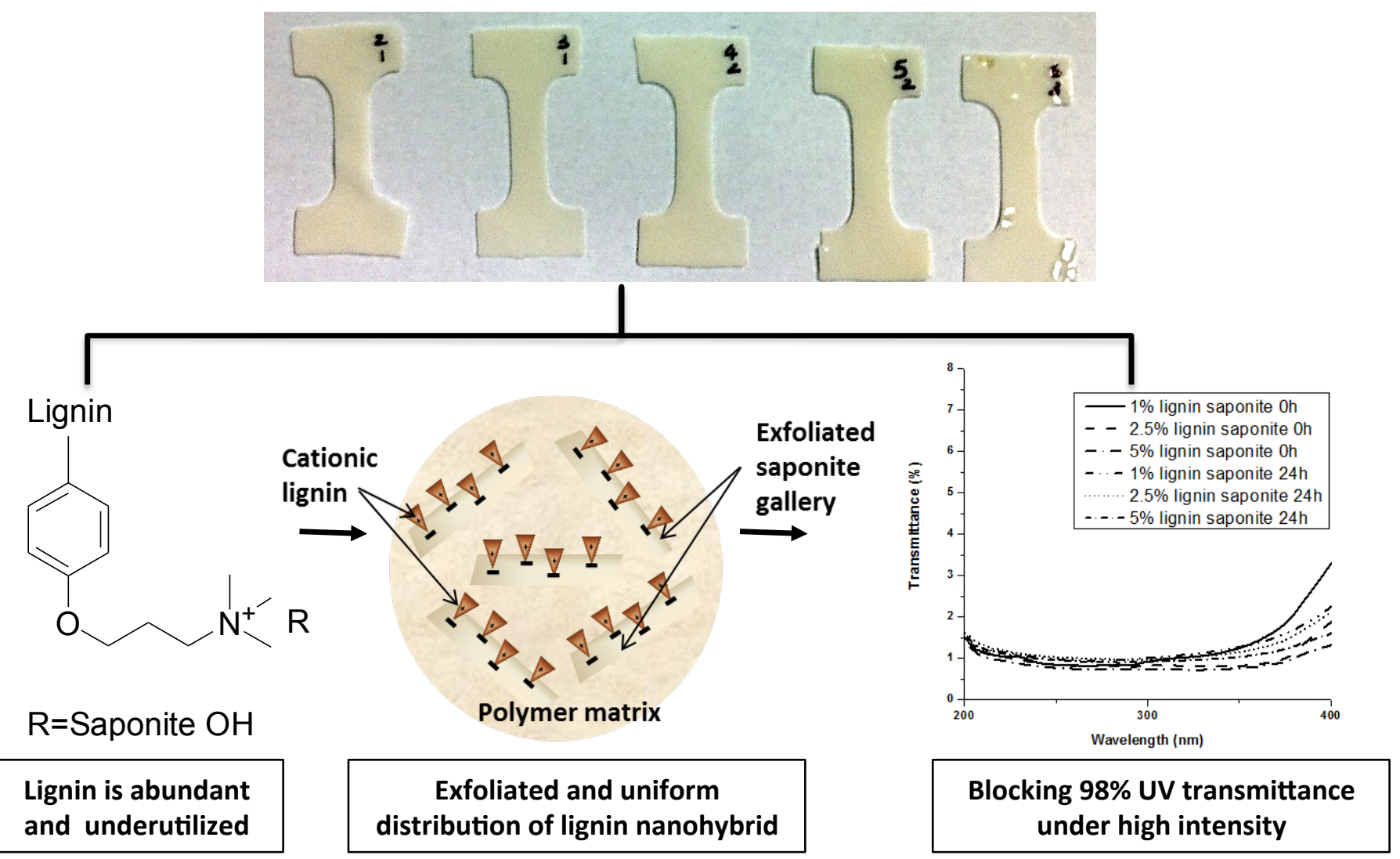

